\title{
Child Health Survellience - Analysis of the Existing Services
}

\section{Rajeev Gupta ${ }^{1 *}$ and Siba Prosad Paul ${ }^{2}$}

${ }^{1}$ Barnsley District General Hospital NHS Trust, Gawber Road, Barnsley, UK

${ }^{2}$ Speciality Trainee in Paediatrics, Great Western Hospital, Swindon, UK

\begin{abstract}
The Child Health Surveillance (CHS) is the core of a healthy childhood programme for the children living in the United Kingdom. The change of the GP contract in 2004 may have significant implications on the CHS services. The GPs will no longer be required to provide a CHS service under their contract requirements and there is a chance that the increase in workload will have to be borne by the HVs and other community practitioners. This is likely to leave gaps in the service provided and may have an indirect effect on children from the deprived social class who are largely dependent on the services provided by the CHS. A questionnaire survey was thus organised in the early years after the implementation of the GP 2004 contract to understand the level of success of the CHS services, deficiencies that may have arose and also how the HVs and GPs are working with each other in an era of changed service contract. The main findings from the study was encouraging that $91 \%$ of the GPs have opted to continue providing the $\mathrm{CHS}$ services, and $>85 \%$ of the surveyed staff group were having dedicated baby clinics once a week. The GPs were mainly doing the newborn checks and the 6 weeks check whereas the other aspects of CHS were largely done by the HVs along with advice on health promotion. Few discrepancies were highlighted from the study, these were taken up and adequately addressed by the Barnsley PCT and the localities managers. We hope this study reflects on the CHS service requirements in light of the new GP contract and will help in delivering service in other PCTs, although regional differences and needs will vary and consideration for that is very important.
\end{abstract}

Keywords: Child Health Surveillance (CHS); General practitioners; Health visitors; Interpersonal relationship and communication; Red book; 2004 revised GP contract

\section{Introduction}

The Child Health Surveillance (CHS) programme (renamed as Healthy Child Programme) is designed to identify physical, developmental and behavioural abnormalities at an early stage. This enables initiation of an effective intervention early [1]. Success of this programme largely depends on a close co-operation and a good working relationship between the medical staff and the community nursing team, in particular the Health Visitors (HVs) [2]. CHS has changed its shape over period of time and the 2004 General Practitioners (GPs) contract [3] has quite significantly changed CHS services provided by the GPs. This was in addition to the option of no out of hours on call services for the GPs. It also had impact on the services provided by HVs which has undergone some reconfiguration. It was felt necessary to do a questionnaire survey by the paediatric team at the Barnsley District General Hospital. This questionnaire was sent to all the GPs and HVs covered under the Barnsley Primary Care Trust to know their practices and the achievements with regards to CHS services since the change of the contract.

\section{Aims and Objectives}

The new GP contract of 2004 was expected to change the way how CHS services will be provided in the future. To understand how it affected the local services in the Barnsley area a questionnaire survey was organised to know the early impact of the contract. This was aimed at addressing any loopholes and deficiencies that may have arose following the change of contract for the GPs and also to facilitate the smooth transition of the services being led by the HVs and other community practitioners. The objectives of the study were simple and aimed at knowing the following:

1. To find out the level of achievement of the CHS activities after the 2004 GP contract.
2. To find the support and interpersonal relationship between the staff group.

3. To find the extent of services provided by the individual GPs \& HVs.

4. To find out possible room for improvements in the existing services.

5. To find the need for further training to provide a quality CHS service.

\section{Materials and Methods}

A predesigned reviewed questionnaire was sent to all GPs and HVs of the Barnsley PCT area. It should be noted that where the GPs worked in a group practice it was the lead partner who was sent the survey questionnaire. In the survey, the respondents were asked to report on the frequency of dedicated baby clinics, neonatal and subsequent pre-school check-ups for children and immunization services, whether the existing facilities were adequate for the CHS activities with special reference to space, equipment available and staff support. For the purpose of the study a scale of 1 to 5 was devised with 1 being excellent and 5 being considered inadequate. Questions about frequency of entries made after a consultation in the Red Book were also included. The HVs questionnaire also included 3 additional queries such as facilities for available waiting space, waiting times before being attended by the HVs and hygiene standards inclusive of hand washing

*Corresponding author: Dr. Rajeev Gupta, Barnsley District General Hospital NHS Trust, Gawber Road, Barnsley - S75 2EP, United Kingdom, E-mail: rajeev. gupta@nhs.net; siba@doctors.org.uk

Received May 28, 2012; Accepted July 18, 2012; Published July 20, 2012

Citation: Gupta R, Paul SP (2012) Child Health Survellience - Analysis of the Existing Services. Primary Health Care: Open Access 2:120. doi:10.4172/2167 1079.1000120

Copyright: (C) 2012 Gupta R, et al. This is an open-access article distributed under the terms of the Creative Commons Attribution License, which permits unrestricted use, distribution, and reproduction in any medium, provided the original author and source are credited. 
Citation: Gupta R, Paul SP (2012) Child Health Survellience - Analysis of the Existing Services. Primary Health Care: Open Access 2:120. doi:10.4172/2167-1079.1000120

Page 2 of 5

facilities, nappy disposal, availability of surface cleaners to be used on surfaces between babies, etc. the responses were devised on a scale of 1 being excellent to 5 being worst or unacceptable. A waiting time of $<15$ minutes was considered as excellent and $>90$ minutes being unacceptable. Also included as responses were the views of the GPs and HVs from the Barnsley PCT on whether they refer children to the community pediatricians and on their working relation with each other and the support extended for the CHS activities. The questionnaire survey tried to find about the level of training received by each of the staff group to undertake the CHS activities. The responses received were compiled, analysed and evaluated by our team and the results are presented below. It is to be noted that the questionnaire sent slightly varied as the clinical services provided by the 2 different group of health professionals is different and the questionnaire survey had taken this in account while being formulated.

\section{Results}

We received 33 responses out of total 43 questionnaires sent to GP (76\%) and all of the 38 questionnaires were received back from the HV (100\%). A further postal reminder was sent but no response was received in 4 weeks. The problem of receiving feedback from the GPs was also highlighted in a recent study in Birmingham wherein only $44 \%$ of the survey questionnaires were returned for analysis [4]. $91 \%$ of the GP surgeries wished to continue providing CHS services, although the 1991 and 2004 revised contract provided the option to opt out of the CHS services. The compiled results are presented here.

\section{Frequency of dedicated baby clinics}

For the study, we considered a dedicated baby clinic as a place where well babies and mothers can meet a health professional for baby's weight, discussion about feeding, weaning, home safety issues, etc.). It may be noted that although not asked as a formal response, some GPs were actually providing these services with the involvement of the

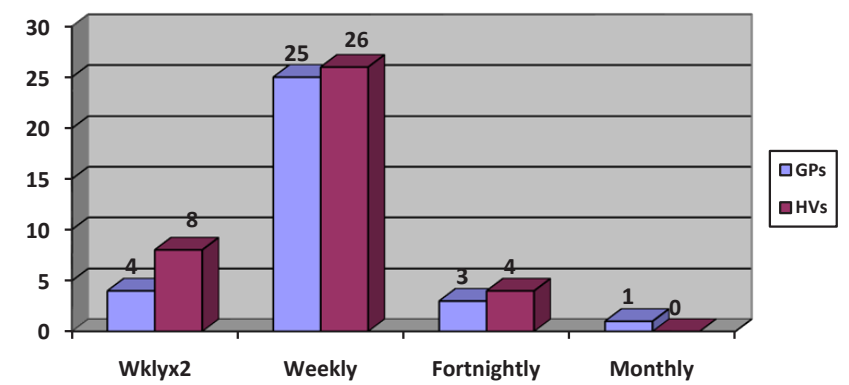

Figure 1: Frequency of dedicated baby clinics.

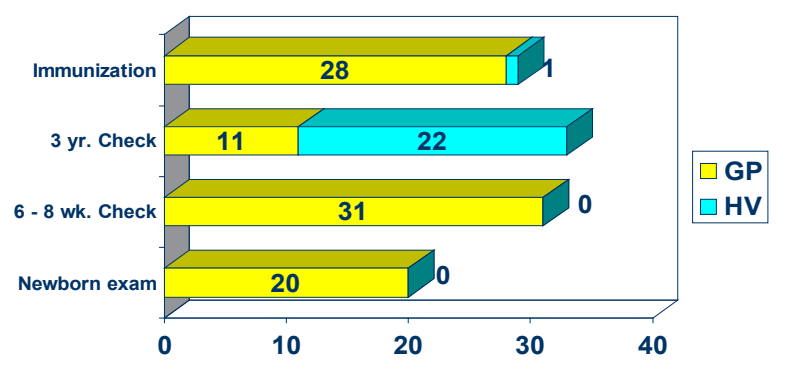

Figure 2: Proportion of work done according to GP questionnaire response. practice nurses. $87 \%$ of the GPs and $89 \%$ of the HVs were conducting such clinics at least once a week. The trend is presented in figure 1.

\section{Developmental checks and immunisation}

The newborn examination, 6-8 week baby checks and the immunisation were mainly conducted by the GPs (Figure 2). However, the other aspects of CHS activities (Figure 3) viz. 7 months, 2 years and $3 \frac{1}{2}$ years check were conducted by the HV. It may be noted that significant proportion of the immunisations were presumably conducted by the practice nurses and the GP response had reflected that under the GP practice.

\section{Response to available facilities for CHS}

For the purpose of the survey a scale of 1 to 5 was devised, with 1 being excellent and 5 being worst for the availability of facilities. The GPs in $63 \%$ of cases reported space was adequate while the HVs felt so in only $42 \%$ of cases. Equipments were perceived to be adequate and in good condition in $70 \%$ responses by the GPs while only $42 \%$ of HVs responded favourably for the same question. Skills mix and staff support were considered adequate in $76 \%$ cases by the GPs while it was only $53 \%$ in the HVs survey. The above 3 parameters are depicted in a scale from excellent to worst in figure 4 and 5 .

\section{Entry of consultation in the red book}

The 'red book' is a personal child health record (PCHR) wherein a record of a child's growth, development, and uptake of preventive health services is documented and is kept with the parents [5]. Also it

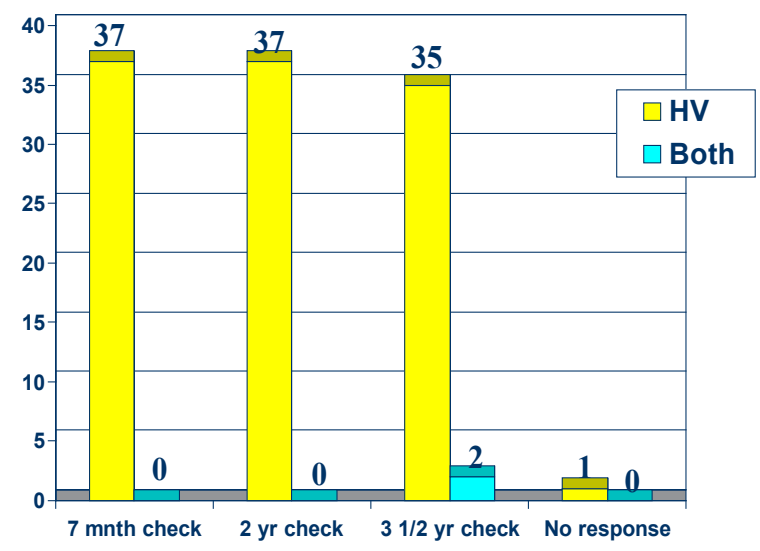

Figure 3: Proportion of work done according to HV questionnaire.

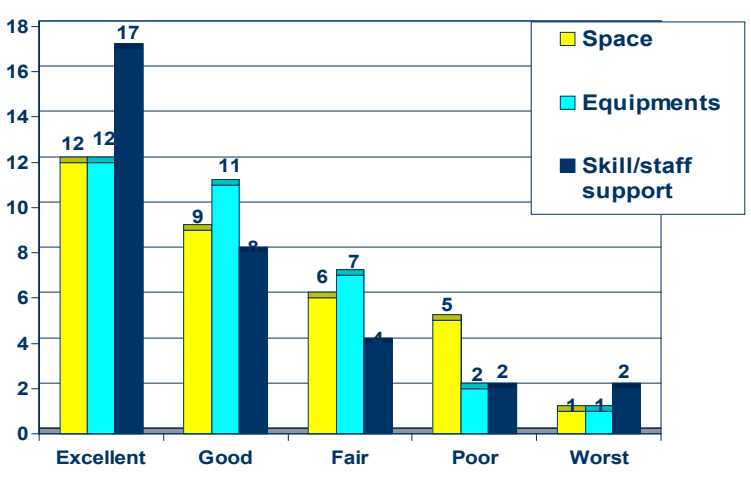

Figure 4: Facilities available for $\mathrm{CHS}$ according to GP questionnaire. 
Citation: Gupta R, Paul SP (2012) Child Health Survellience - Analysis of the Existing Services. Primary Health Care: Open Access 2:120. doi:10.4172/2167-1079.1000120

Page 3 of 5

is designed to enhance the communication between parents and multidisciplinary health professionals by documentation of the consultation and advice given. Record of such entries from the survey is depicted in figure 6 .

\section{Aspects for a consumer friendly service}

Privacy, waiting time and hygiene standards were perceived as good in about $50 \%$ of the responses but interestingly enough $24 \%$ of $\mathrm{HV}$ responses reported inadequate hygiene standards and hand washing facilities. These responses were only specifically enquired about in the HVs questionnaire survey in a scale of 1 being excellent to 5 being unacceptable, is depicted in table 1.

\section{Staff group ratings of their working relationship and the support extended to each other}

While $65 \%$ of the HVs perceived support from the GPs to be good, $85 \%$ of the GPs reported it to be good from the HVs. As regards to the response about interpersonal working relationship with each other, $58 \%$ of the HVs reported to have good relationship with the GPs, the GPs responded so in $79 \%$ of cases. The responses about support received and interpersonal relationship are highlighted in table 2.

\section{Referral to the community paediatricians}

GPs were less likely to refer to the associate specialists in the community paediatrics department as compared to the HVs. This is presented in table 3.

8 GPs also responded that they either do not know who the designated associated specialist assigned for their area or are not aware

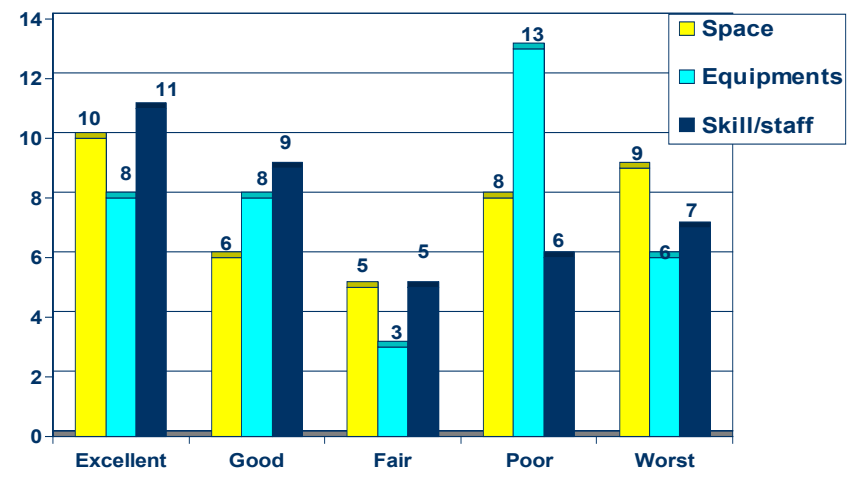

Figure 5: Facilities available for CHS according to HV questionnaire.

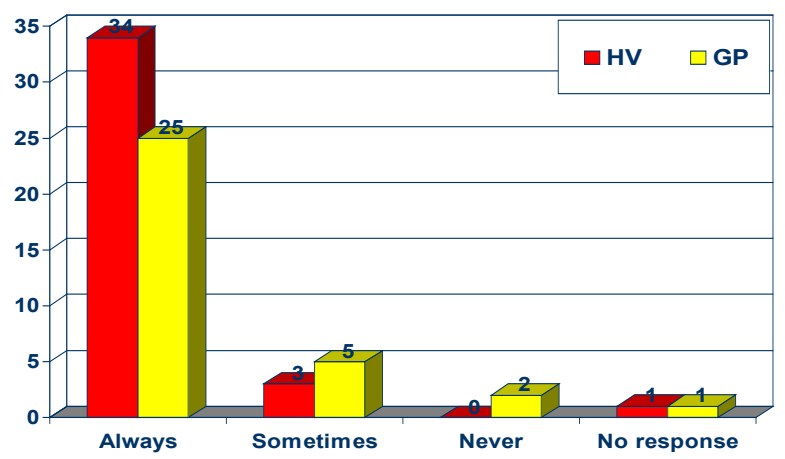

Figure 6: Maintenance of $\mathrm{CHS}$ records ( Red book ) according to HV \& GP response.

\begin{tabular}{|l|l|l|l|}
\hline Scale of response & Privacy & Waiting times & Hygiene standards \\
\hline Excellent (1) & $11 / 38(29 \%)$ & $9 / 38(24 \%)$ & $16 / 38(42 \%)$ \\
\hline Good $(2)$ & $8 / 38(21 \%)$ & $8 / 38(21 \%)$ & $8 / 38(21 \%)$ \\
\hline Fair $\quad(3)$ & $5 / 38(13 \%)$ & $7 / 38(18 \%)$ & $5 / 38(13 \%)$ \\
\hline Poor $\quad(4)$ & $7 / 38(18.5 \%)$ & $9 / 38(24 \%)$ & $4 / 38(11 \%)$ \\
\hline Worst $\quad(5)$ & $7 / 38(18.5 \%)$ & $5 / 38(13 \%)$ & $5 / 38(13 \%)$ \\
\hline
\end{tabular}

Table 1: HVs response on consumer friendly facilities.

\begin{tabular}{|c|c|c|c|c|}
\hline Response & $\begin{array}{l}\text { GPs on the } \\
\text { support from } \\
\text { HVs }(n=33)\end{array}$ & $\begin{array}{l}\text { HVs on the } \\
\text { support from } \\
\text { GPs }(n=38)\end{array}$ & $\begin{array}{l}\text { GPs on their } \\
\text { relationship with } \\
\text { HVs }(n=33)\end{array}$ & $\begin{array}{l}\text { HVs on their } \\
\text { relationship with } \\
\text { GPs }(n=38)\end{array}$ \\
\hline Excellent & $11(33 \%)$ & $5 \quad(13 \%)$ & $24(73 \%)$ & $17(45 \%)$ \\
\hline Good & $15(46 \%)$ & $20(53 \%)$ & $4 \quad(12 \%)$ & $5 \quad(13 \%)$ \\
\hline Fair & $5 \quad(15 \%)$ & $4 \quad(10.5 \%)$ & $3 \quad(9 \%)$ & $5 \quad(13 \%)$ \\
\hline Poor & $2 \quad(6 \%)$ & 0 & $1 \quad(3 \%)$ & $1 \quad(2 \%)$ \\
\hline Worst & 0 & $1 \quad(2.5 \%)$ & $1 \quad(3 \%)$ & $3 \quad(9 \%)$ \\
\hline No response & 0 & $8 \quad(21 \%)$ & 0 & $7 \quad(18 \%)$ \\
\hline
\end{tabular}

Table 2: Staff group response on support and interpersonal relation.

\begin{tabular}{|l|l|l|}
\hline Response from the staff group & GPs $(n=33)$ & HVs $(n=38)$ \\
\hline Yes & $14(42.5 \%)$ & $37(97 \%)$ \\
\hline No & $17(51.5 \%)$ & 0 \\
\hline No response & $2(6 \%)$ & $1 \quad(3 \%)$ \\
\hline
\end{tabular}

Table 3: Staff group response on referral to associate specialists.

of such services. The nature of the problems referred to the associate specialists are highlighted in figure 7.

\section{Response on the aspect of training for CHS activities}

It may be noted that 14 out of 33 GP (42.5\%) had actually worked as paediatric senior house officer ( $\mathrm{SHO}$ ) whereas 5 responded as having no training $(15 \%)$. The training received is highlighted in table 3 , it is to be noted that some GPs have worked as a SHO and did other training such as a course on CHS, etc.

All the HVs however have received a formal training during their student years on CHS i.e. prior to qualifying as HVs. The question for this group was therefore requested as and when they had their last training on $\mathrm{CHS}$ which is depicted in figure 8.

\section{Discussion}

Most of the GPs opted to continue providing CHS services even after the implementation of the 2004 GP contract, similar theme was highlighted in a study investigating the early stages of the contact [6]. The survey revealed that $9 \%$ of the GP surgeries responded as having opted out of the CHS activities, appointment of some part-time GP or health practitioners with special interest dedicated towards conducting CHS activities were thought necessary. This was also observed in a study by Leese [7], the 1990 GP national contract of "one size fits all" type was failing by the mid 1990s to serve the needs of the GP and the patients in some areas of the country, particularly noted in the deprived areas of the inner cities. In a study in East London [8] in 2000, $62 \%$ of the practices were registered for $\mathrm{CHS}$ activities and $71 \%$ provided a service for child health clinic. This study reflected a better involvement by the GP surgeries. The appointment $[9,10]$ of the practice nurses keeping in view of the 1990 GP contract may also considered a step towards delineating CHS services as some of the practice nurses were taking up the role of administering vaccinations [11]. The fact that many GP did not consider CHS as part of their normal duty, was also highlighted in a survey in Newcastle [11] which showed that 40 out of the 51 practices were routinely offering preschool child health surveillance and 47 were 


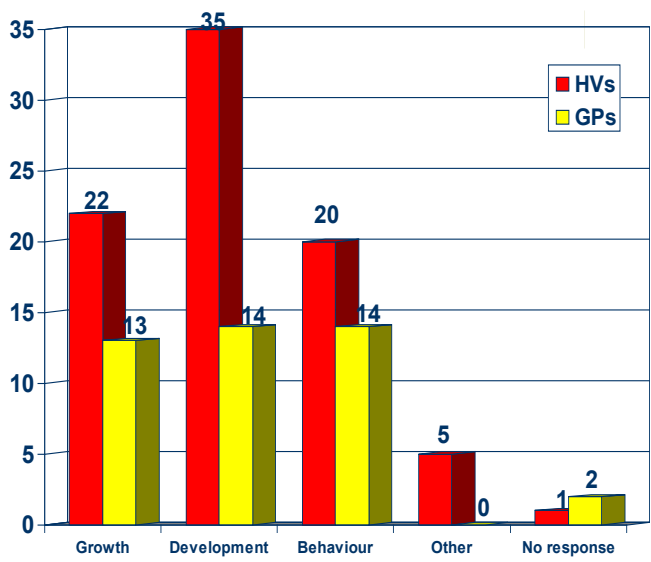

Figure 7: The nature of problems reffered to the associate specialists.

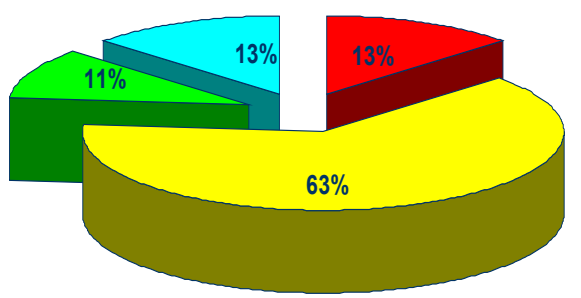

$\square<1$ year $\square 1-5$ year $\square$ While as HV trainee $\square$ No response

Figure 8: Formal training last received in $\mathrm{CHS}$ as responded by the HVs.

undertaking preschool immunization by working closely with their attached health visitors to provide the service.

The analysis revealed involvement of both the groups in the 3 to $3 \frac{1}{2}$ years checks, it may be that the GPs are doing the clinical bit of the check-ups while HVs are doing the growth and development issues along with the aspects on health promotion. This pattern would be supported by GPs shifting their service more towards clinical care and HVs being responsible for the health surveillance [7,12]. The role of HVs in growth and developmental monitoring issues also reflects their role as part of a family oriented care package [12]. The Swedish health surveillance programme 3 included 15 examinations by a nurse, 5 examinations by a physician, 7 assessments of development, 2 assessments of hearing and 1 assessment of visual acuity which are comparable to the CHS activities provided by the HV and GP under the NHS. In a study in Nottingham [13] in 2002, HV were more likely to discuss about the health promotion during the CHS in contrast to the GP who concentrated more on clinical aspects. The discrepancy highlights that the HV are more geared up to make sure a family oriented care is provided as most of the consultation will be for a well child but may have issues [12] e.g. obesity, short stature, mild anaemia, safety issues at home, etc. It is important that the health promotion advices provided by the $\mathrm{HV}$ are tailor made for the individual families so as to empower the parents in making heath choices which will be helpful for their children [12]. The role of the HVs in detecting and caring for children with mental health issues was also found to be substantial and important from a survey in Scotland [14]. The study highlighted that the CHS activities are not regularly entered in the 'Red Book'. However, it is not unlikely that the parents in some cases are not made aware of the record keeping issue and may be not bringing the 'Red book' to every CHS consultation. HV can address this with the parents during their home visits or clinic consultations. This would fit in with the observation of an unpublished study [15] (S. Hallworth, personal communication) which suggested that forms are filled in less completely by GP than by community medical officers or HVs. This issue was also highlighted in a study involving mothers of 18503 children born between 2000 and 2002, living in the UK at 9 months of age wherein 16917 (93\%) mothers produced their child's PCHR and 15138 (85\%) mothers showed effective use of their child's PCHR [5]. It was highlighted that the use of the PCHR is lower by women living in disadvantaged circumstances.

As HVs perceived inadequacy of space and privacy for the consumer, it necessary to address with an aim to make the clinics baby and user friendly [16]. Equipments need to be replaced or updated and made easily available for the CHS activities. As $23 \%$ of the $\mathrm{HV}$ responses expressed concern in regards to the existing hygiene standards, with some surgeries even lacking basic amenities for hand washing, steps were taken to address the issue.

Similar issues were highlighted in a study in Nottingham wherein additional resources were channelled for making health promotion more accessible and directed towards the user necessities in a deprived area [17]. A study in the Clifton area in Nottingham [18], between 1983-1999 showed a definite change in trend with the community paediatricians in 1983 being more involved in delivering primary health care (viz. CHS activities) whereas in the next decade there was a shift towards providing secondary care. This was comparable to our questionnaire survey where most referrals to Associate specialists were issues concerning development, growth, behaviour, enuresis, allergies, etc. rather than for routine developmental baby checks. The support and interpersonal relations between the GPs and HVs is necessary for success of the CHS programme. In an interview survey involving $40 \mathrm{HVs}$ in Cambridge; it was highlighted that for a good working relationship between the HVs and the GPs, each must appreciate the other's role. Good accommodation, working under the same roof and devices such as attachment and the primary health care team may help, but it is the nature of the communication between the two professionals which is vital for the preservation and improvement of standards in community medical practice [2]. In a UK based survey of HV in 1992, only 56\% of respondents reported as having enough background information available regarding injury prevention practice $[19,20]$ which forms a significant part of health visiting practice. Also there is an evolving role of the practitioners with special interests who would be providing for the CHS activities [7]. There may also be a role for the GP with special interest to do a special clinic like enuresis, but adequate training needs are to be addressed [7-9].

\section{Recommendations}

The questionnaire survey analysed by the team found out few areas of concern and has made the following useful recommendations which highlights the issues that evolved from the study and also from the available literature review on the issue $[2,12,13,17,18,21]$ :

1. To improve the co-ordination for providing a better $\mathrm{CHS}$ service, regular meetings are necessary between the GPs, the HVs and the practice nurses.

2. To increase the awareness for the GPs about the community paediatric services available in order to make early referrals. 
3. Increase awareness about the CHS recommendations by regular update meetings.

4. To improve the facilities for child health promotion activities by discussion with the localities manager to address the issue.

5. To provide urgent improvement of the hygiene standards by making hand washing and nappy disposal facilities available in every clinic.

6. To provide educational opportunities to the GPs and HVs by arranging a monthly session on common paediatric conditions in addition to the CHS updates.

7. To train healthcare professionals with special interest for immunisations, health promotion, etc. which seems to be an evolving trend to provide better CHS services.

\section{Limitations of the Study}

The study was limited by the fact that the data analysis was wholly dependent on the responses received. There was no face to face contact or telephonic conversation undertaken. The non-availability of the 10 survey questionnaire (23\%) from the GPs (may have skewed the responses from this particular staff group. In the case of a group practice the response from the senior/lead partner was requested and will have some restriction of the views that the other partners may have differed. The HVs relation was felt not so cordial in some cases and it was difficult for us to make a conclusion whether these were the cases where a response from the GPs were not received and hence may have given more useful on the interpersonal relationship aspects. Also there are regional differences on how the PCTs deliver CHS services and may not be applicable to all the counties in the UK.

\section{Conclusion}

This questionnaire survey highlighted a significant achievement towards providing better CHS services. Few issues were highlighted which were appropriately addressed. This study defines a definite change in trend towards a family oriented care being provided by the HVs who will pick up on the health promotion issues that would have previously got delayed due to lack of health awareness. With the involvement of HVs in the services parents are more likely to highlight the minor concerns like development of speech or a delay in walking. We hope this study heightens the awareness amongst the HVs and GPs about the necessity to address issues that may be persistent to their practice and the need to sort those so as to provide better CHS service.

\section{Suggested Key Points}

1. Child Health Surveillance (CHS) is the key for a healthy child in the society.

2. CHS identifies physical, developmental and behavioural abnormalities at an early stage.

3. A good working relation and communication is necessary amongst the Health visitors and the General practitioners for the success of the CHS programme.

4. The 2004 revised GP contract has implications on how the CHS services may be provided in the future.

5. HVs has an important role in the family-oriented care.

6. Other community practitioners e.g. the practice nurses, community nurses, are increasingly getting involved in the CHS activities.

7. Regular updates and training is necessary to provide a good quality CHS service.

8. The 'red book' is an important document and should be filled in every consultation.

\section{References}

1. http://news.bbc.co.uk/go/pr/fr/-/1/hi/health/2779473.stm

2. Checkland K, Harrison S, McDonald R, Grant S, Campbell S, et al. (2008) Biomedicine, holism and general medical practice: responses to the 2004 General Practitioner contract. Sociol Health IIIn 30: 788-803.

3. GP Contract: At a glance. Story from BBC News.

4. Boyd M, Chubb A (1994) Health visiting: a new model for a deprived area. Int J Health Care Qual Assur 7: 8-11.

5. Draper J, Farmer S, Field S, Thomas H, Hare MJ (1984) The working relationship between the general practitioner and the health visitor. J R Col Gen Pract 34: 264-268.

6. Wilson P, Furnivall J, Barbour RS, Connelly G, Bryce G, et al. (2008) The work of health visitors and school nurses with children with psychological and behavioural problems. J Adv Nurs 61: 445-455.

7. Leese B (2007) New opportunities for nurses and other healthcare professionals?: A review of the potential impact of the new GMS contract on the primary care workforce. J Health Organ Manag 20: 525-536.

8. Hull S, Harvey C, Sturdy P, Carter Y, Naish J, et al. (2000) Do practice-based preventive child health services affect the use of hospitals? A cross-sectional study of hospital use by children in east London. Br J Gen Pract 50: 31-36.

9. McDonald R, Campbell S, Lester H (2009) Practice nurses and the effects of the new general practitioner contract in the English National Health Service: The extension of a professional project? Social Science \& Medicine 68: 12061212.

10. Changing the face of general practice. Practice Nursing 13: 332.

11. van Zwanenberg TD (1991) Effect of the new GP contract on child health clinics. Arch Dis Child 66: 157-159.

12. Taylor C (2005) Developments in child health surveillance programmes. Nurs Times 101: 32-34.

13. Hampshire AJ, Blair ME, Crown NS, Avery AJ, Williams El (2002) Assessing the quality of preschool child health surveillance in primary care: a pilot study in one health district. Child Care Health Dev 28: 239-249.

14. www.dh.gov.uk

15. Gillam SJ, Colver AF (1993) Preschool child health surveillance. Qual Health Care 2: 129-133.

16. Pre-School Child Health Promotion Policy: Core Programme (2003) BDGH NHS Trust \& Barnsley PCT.

17. Walton S, Bedford H, Dezateux C; Millennium Cohort Study Child Health Group (2006) Use of personal child health records in the UK: findings from the millennium cohort study. BMJ 332: 269-270.

18. Didcock E, Polnay L (2001) Pioneers, paediatricians and public health: the evolution of community child health services, Clifton, Nottingham 1983-1999. Public Health 115: 412-417.

19. Woods AJ (2006) The role of health professionals in childhood injury prevention: a systematic review of the literature. Patient Educ Couns 64: 35-42.

20. Carter YH, Bannon MJ, Jones PW (1992) Health visitors and child accident prevention. Health Visit 65: 115-117

21. Brown K, Hampshire M, Groom L (1998) Changes in the role of genera practitioners in child health surveillance. Public Health 112: 399-403.

22. Bremberg $S$ (2000) Quality of evidence for the present Swedish child health surveillance programme. Acta Paediatr Suppl 89: 8-11.

23. Blair ME, Pullan CR, Rands CE, Crown N (2000) Community paediatrics moves on - an analysis of changing work patterns 1994-97. Public Health 114: 61-64. 